\title{
STARS IN THE ORIGIN AND EVOLUTION OF SPECIES
}

\author{
Y. V. Subba Rao ${ }^{1 凹}$ (iD)
}

${ }^{1}$ Executive Engineer (Retired), University Science and Instrumentation Centre, Sri Venkateswara University, Tirupati, Andhra Pradesh State, India.

Received 4 September 2021

Accepted 17 September 2021

Published 30 September2021

\section{CorrespondingAuthor}

Y. V. Subba Rao,

yvsubbarao2004@yahoo.com

DOI

10.29121/granthaalayah.v9.i9.2021. 4282

Funding: This research received no specific grant from any funding agency in the public, commercial, or not-for-profit sectors.

Copyright: (C) 2021 The Author(s). This is an open access article distributed under the terms of the Creative Commons Attribution License, which permits unrestricted use, distribution, and reproduction in any medium, provided the original author and source are credited.

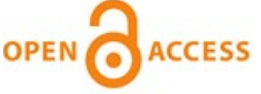

\section{ABSTRACT}

The proposed hypothesis of 'Stars in the Origin and Evolution of Species' is based on the principle underlying in 'Jyotish', one of the six Vedāngas and ancillary of most ancient Vedas of Hinduism. The principle of interaction of electromagnetic force with inorganic chemistry available to us in the universe defines life as an emergent property of matter and as the most plausible hypothesis for explaining the extra-terrestrial origin of species. The current hypothesis of evolution explains the critical milestones in the development of advanced life on Earth during the Cambrian explosion and the complexity of life when humans appeared on earth endowed with a brain of extraordinary intellectual capacities and capabilities which is far more complex than the animal brain and its development in stages is also observed as a plausible mechanism in tune with the phases of elements given out by the stars during their life cycles.

Keywords: Jyotish, Extra-Terrestrial, Origin of Life, Evolution, Cambrian Explosion, Human Brain

\section{INTRODUCTION}

\section{Highlights}

- 'Jyotish', ancillary of the Vedas of Hinduism, is the life side of Astronomy.

- Principle of 'Jyotish' is interaction of sunlight (electromagnetism) and stars (matter).

- Life is defined as an 'emergent property of matter and transformed into energy'.

- The law of conservation Energy is like Atman (Soul) in Hinduism

- 'Jyotish' unravels the mystery of 'Origin of Life' and Evolution.

Jane Taylor wrote the children's poem 'The Star' which we now know as 'Twinkle, Twinkle, Little Star', How I wonder what you are! Twinkle (1947). We also wonder what it is, not knowing that we are made of star dust. But it is poetic to say that we are made of star dust. Amazingly, it is true because our bodies and our planet are made of elements born out of the explosion of massive stars. In one of the plays of William Shakespeare "Julius Caesar", Caesar says to his wife Calpurnia: "When beggars die, there are no comets seen; The heavens themselves blaze forth the death of princes." It is true in Hinduism where highly enlightened souls become 'stars. The young Prince and legend Dhruva through his meditation became the tail end star 'Polaris' of the constellation 'Ursa Minor' in the northern hemisphere. It is like many great sages becoming 'saptarishis' meaning 'seven sages' as the seven stars constituting the constellation 'Ursa Major', situated a little down below 'Ursa Minor', with two of its stars in line with the 'Polaris' 
(Figure 1: Ursa Major (Saptarishi Mandalam) and Ursa Minor (Dhruva Mandalam) Vedic Thought and Modern Genetics on Consanguinity.

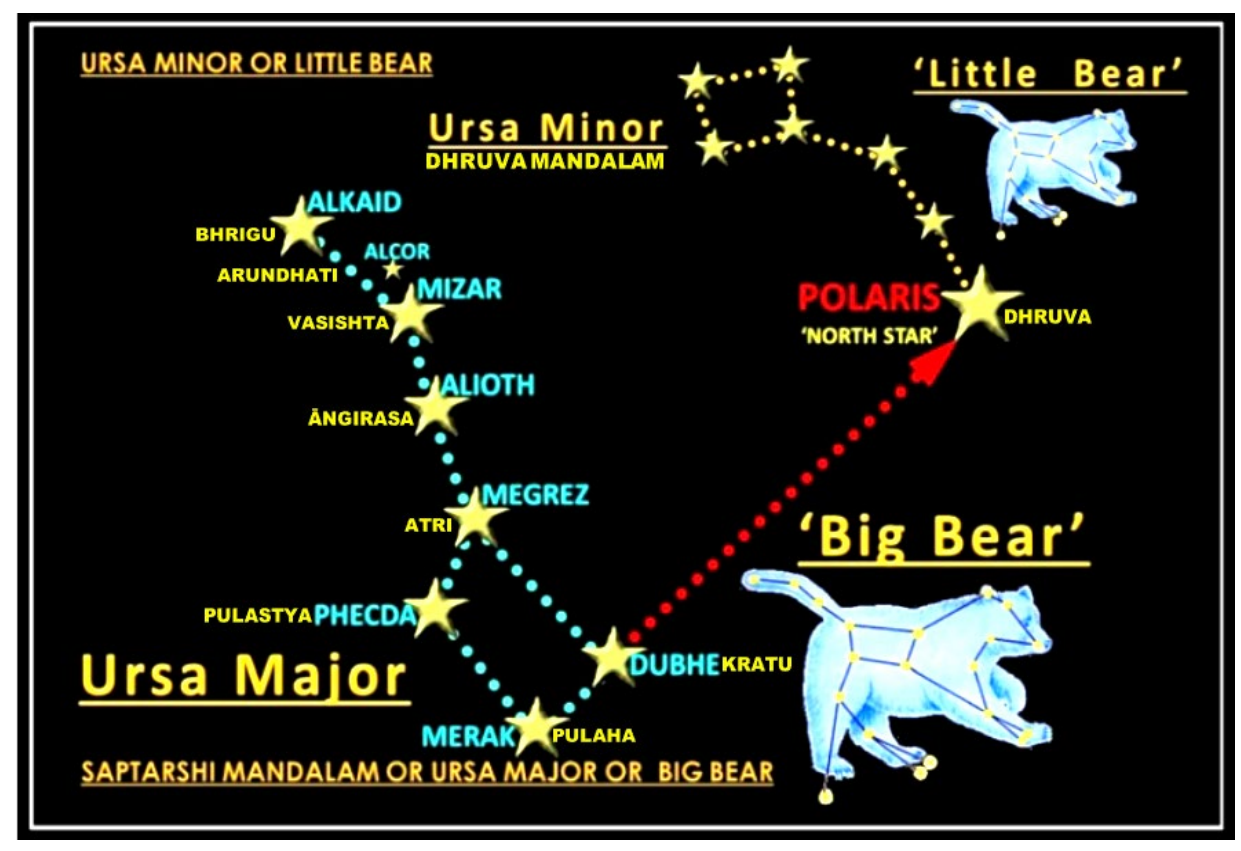

Figure 1 Ursa Major (Saptarishi Mandalam) and Ursa Minor (Dhruva)

\subsection{PRINCIPLE UNDERLYING IN 'JYOTISH', ONE OF THE SIX VEDĀNGAS}

'Jyotish' (Astrology), one of the six Vedāngas and ancillary of most ancient Vedas of Hinduism. Jyotish is considered part of the science of astronomy, astrophysics, astrochemistry and astrobiology and had its glory in the past in India. In fact, the famous Varahamihira (520 AD) was an Indian astronomer and astrologer par excellence in the court of King Vikramaditya. Consequent of continuous invasions and centuries of colonial rule distanced the real great science from the people. Now, however, astrology is commonly considered a pseudoscience by the academia of the world without exploring the modern sciences such as astronomy, astrophysics, astrobiology, astrochemistry, etc., latent in it.

Sunlight is essential for flora and fauna to flourish on earth. Earth receives sunlight from the solar system. The selective adaptation of celestial bodies of solar system for its studies in 'Jyotish' (Astrology) is that they are all responsible for the sunlight on earth. as means of its studies which purely rests on the effects of electromagnetism in the form of sunlight. Besides this, Jyotish also selectively adapted of all the 88 constellations of the zodiac lying in the' Milky Way' of our Galaxy by grouping them into 27 Lunar constellations, lying equidistant by $131 / 30$ along the ecliptic, which distance the Moon transits in one day. The constellations of 
the zodiac are made up of stars; they are inside the Milky Way but outside the solar system. Also, the stars are really at very great distances from each other though they appear near each other in the sky.

Stars give out specific chemical elements which is 'matter' in other words known as energy perceivable at lower frequency. Concerning matter, "we have been all wrong. What we have called matter is really 'Energy', whose vibration has been lowered as to be perceivable to the senses. There is no matter. There is only light and sound" - Albert Einstein. There is absolutely no difference in material between the living and the non-living. The living has matter, life and energy while these are dormant in non-living.

Electromagnetic Force does a miracle in forming 'Matter'. A great majority of stars emit most of their electromagnetic energy as visible light. Wavelength correlates with energy and the colour of a star tells us how hot it is. Red colour stars are coolest, blue colour stars are hottest. The miracle of sunlight transforms matter into life, for example photosynthesis. 'Life' can thus be defined as an 'emergent property of matter'. Life transforms itself into energy as is evident in animals. This energy at low frequency obtains higher value tending to infinity in tune with the equation $\mathrm{E}=\mathrm{mc} 2$ in highly enlightened souls when it becomes unperceivable and either absorbed in the absolute or become a star. Thus, stars which give out elements, i.e., matter which is also known as energy at low frequency, on attaining higher frequency through transcendental consciousness in a 'Saint', the saint either obtains liberation or becomes a star'.

Carl Sagan, cosmologist, says "The surface of the Earth is the shore of the cosmic ocean. Some part of our being knows this is where we came from. We long to return, and we can, because the cosmos is also within us. We're made of star stuff. We are a way for the cosmos to know itself." "The nitrogen in our DNA, the calcium in our teeth, the iron in our blood, the carbon in our apple pies were made in the interiors of collapsing stars. We are made of starstuff." - Carl Sagan Populating the periodic table.

When the Big Bang happened, more precisely 12.96 billion years ago, and between 100 and 300 seconds after the Big Bang, atoms of hydrogen were fused together to make helium and heavier elements like lithium and a little bit of beryllium. In after 5 minutes' time, the Universe wasn't star-like anymore for fusion to happen all the other elements in the Universe, including the carbon in our bodies to the precious metal gold were manufactured inside of stars. Western Astronomy is of recent origin, while the ancient Hindu Astronomy is at least as old as the universe as seen in 'Jyotish', one of the six Vedāngas and ancillary of most ancient four Vedas of Hinduism. The theory of stars is the most plausible hypothesis for explaining the origin of species.

\section{CLASSIFICATION OF STARS}

The human life cycle is about eighty years (infant, toddler, child, adolescent, teenager, adult, mature adult, senior citizen, super senior citizen. Most people can identify the various stages of the human life cycle that is observable all around us, and put those stages in sequence. Astronomers have the same task cut out to them when classifying stars. All elements from atomic numbers 1 (hydrogen) to 118 have been discovered or synthesized, with the most recent additions have given rise to the modern periodic table of chemists. Jennifer Johnson, (2008), an astronomer explained what the stars were made of and what they are becoming Jennifer (2019). She concluded that most atoms in our bodies were forged in stars, and the cosmic processes are as varied as the atoms they produce. Johnson and her collaborating 
astronomers frustrated by the misinformation regarding origin of atoms decided to determine what atoms come from what stars, and the point in the stars' life cycles when they are formed. They crafted and split the common periodic table down to commonly occurring elements according to their origin and designed the updated table in 2008. The new version of Johnson's Periodic Table of Elements as posted on her blog, focuses on stable, non-radioactive elements.

The elements are color-coded by their cosmic origins. It shows a handful of light elements formed by Big Bang fusion (specifically, Hydrogen and Helium) or cosmic ray fission (specifically, Beryllium and Boron), most lighter elements created by exploding massive stars or white dwarfs. Heavier atoms, from Strontium to Uranium formed in merging neutron stars or dying low-mass stars. Since most elements likely formed under more than one process, the chart codes them by more than one colour, with the approximate amount due to each process (big bang fusion; exploding massive stars; exploding white dwarfs; dying low mass; and merging neutron stars) indicated (Figure 2).

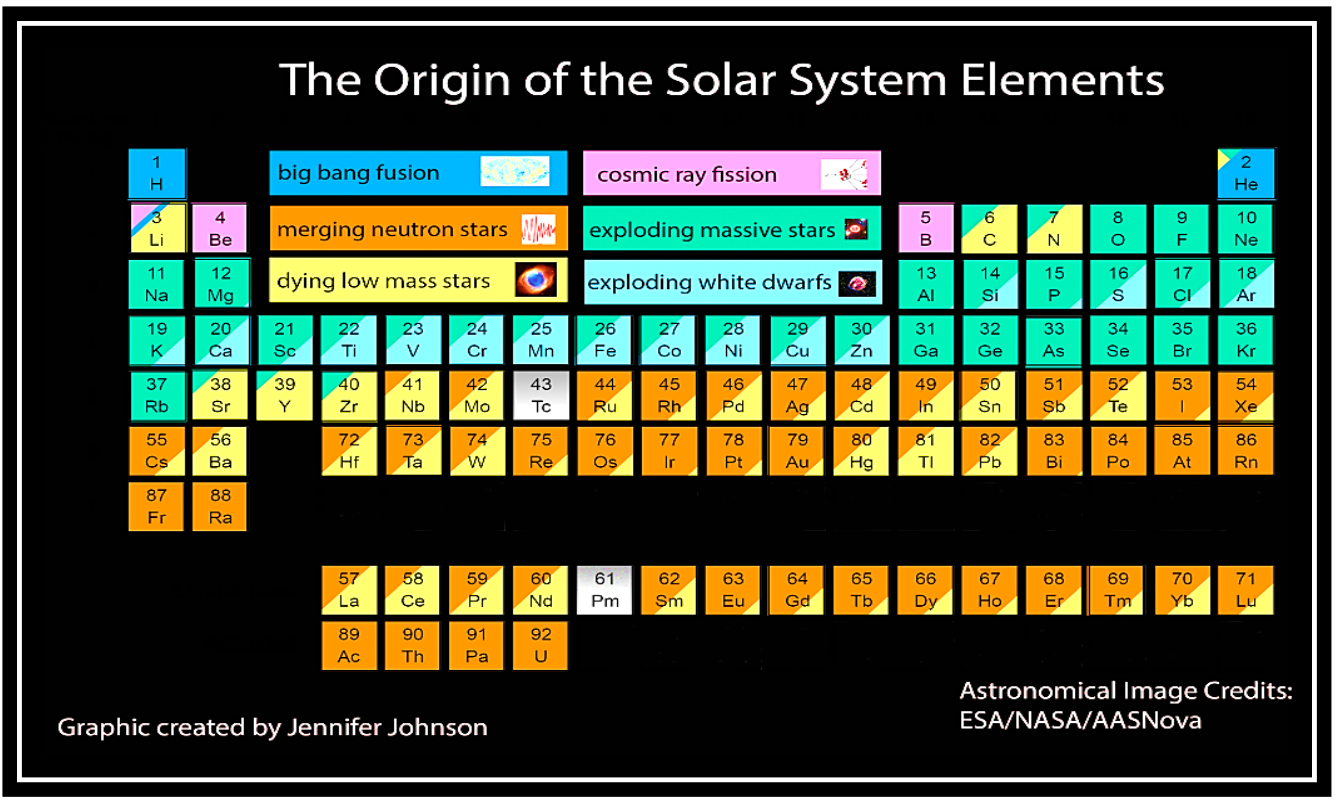

Figure 2 Jennifer Johnson's Periodic Table of Elements as Posted on Her Blog: https://blog.sdss.org/author/jajohnson51/

\section{STAR BIRTH AND LIFE CYCLES OF STARS}

A star is born when gravity pulls all the materials of enormous cloud of gas and dust spread many light-years across together into a giant ball. Enormous temperatures reaching to millions of degrees at the centre of the ball occurs due to the pressure of all the surrounding material. The gas and dust start to glow and shine as a star with the occurrence of nuclear fusion in the form electromagnetic radiation. The stars are born in a variety of sizes and colours. Everything of a star depends on its mass. A star's mass is determined by the amount of matter that is available in its nebula. The giant cloud of gas and dust from which a star was born is called 'nebula' and the life cycle of a star is determined by its mass; greater the mass, shorter is its life cycle. Thus, stars are known as 'massive' stars and so on., 'low or medium mass' stars with their lifetime ranging from perhaps a few million years to more than 10 billion years. Stars create new elements in their cores by squeezing elements together in a process called nuclear fusion. First, stars fuse hydrogen atoms into 
helium. Helium atoms then fuse to create beryllium, and so on, until fusion in the star's core has created every element up to iron (Figure 3).

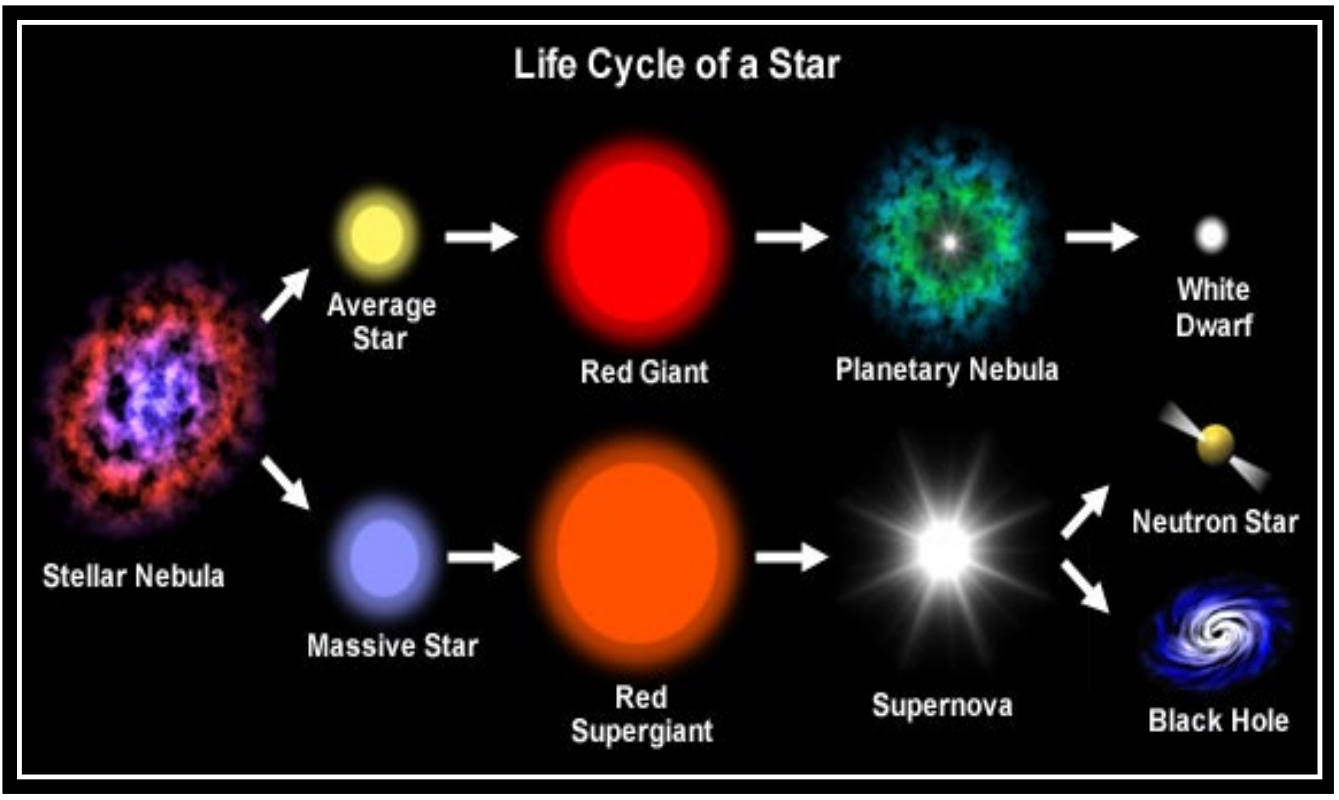

Figure 3 Life Cycle of a Star: PPT - THE LIFE CYCLE OF A STAR PowerPoint Presentation, free download - ID:5438954

\section{ORIGIN AND EVOLUTION OF SPECIES AT REGULAR INTERVALS OF GEOLOGICAL TIME SCALE}

The stars give out specific chemical elements at different phases of their life cycles constituting the inorganic chemistry available to us in the universe and form organic molecules as life building blocks under abiotic conditions and plausibly spontaneously synthesise into protocells and finally give rise to living cells through resonant electromagnetism in the panspermia origin of life wherein the origin of the cell and plausibly the origin of DNA is synchronous. Stars give out elements at different phases of their life cycles plausibly giving rise to origin of different species evolving at regular intervals of Geological Time Scale with specific DNA sequences.

Geological Time Scale delineating the evolution of species is a plausible reflection of Periodic Table of Elements. Stars are the source of all the inorganic elements of the periodic table. A star's life cycle is determined by its mass. The larger its mass, the shorter its life cycle. A star's mass is determined by the amount of matter that is available in its nebula, the giant cloud of gas and dust from which it was born. Elements are formed in Stars when a typical star begins as a thin cloud of hydrogen gas that, under the force of gravity, collects into a huge, dense sphere. When the new star reaches a certain size, a process called nuclear fusion ignites, generating the star's vast energy. The fusion process forces hydrogen atoms together, transforming them into heavier elements such as helium, carbon and oxygen. When the star dies after millions or billions of years, it may release heavier elements such as gold. Nuclear fusion, the process that powers every star, creates many of the elements that make up our universe. Only the bigger stars can produce heavier elements. 


\section{TEN INCARNATIONS AND GEOLOGICAL TIME SCALE}

British geneticist and evolutionary biologist, J B S Haldane, observed that the Dasavataras (ten principal avatars of Lord Vishnu) are a true sequential depiction of the great unfolding of evolution The India magazine of her people and culture. The avatars of Vishnu show an uncanny similarity to the biological theory of evolution of life on earth [7]. He suggested that Dasāvatār (Ten incarnations) gave a "rough idea" of vertebrate evolution. Hinduism was the first to explain the "Theory of Evolution of Life on Earth'. Here, the western Darwinian evolution theory differs from the Rig Vedic Incarnation theory. Rig Veda mentions that evolution is cyclical. Meaning, once every life form on earth perishes, we will again see evolution repeating itself from aquatic creatures to humans again and again. Stars produce specific chemical elements at distinct phases in their life cycles, it could turn out that planets produce/originate living cells of specific life forms and propelled to the earth by star dust for evolution at regular intervals of geological time scales as revealed by distinct phases in their evolution denoted in the Geological Time Scale (Table 1).

- Matsya the fish, an aquatic organism - 500 - 550 MYA - PreCambrianSilurian

- Koorma, the tortoise, an amphibian - 358.9 - 419.2 MYA - Devonian

- Varāha, wild boar - a vertebrate land animal - 200 - 250 MYA - Triassic

- Narasimha- half man- half animal (lion) 66 - 56 MYA - Cretacious

- Vāmana, the Dwarf man underdeveloped man and the First human form, complete human endowed with brain - 0.01 - 2.6 MYA Quarternary

- Parasurāma, the present-day tall humans 0.01 - 2.6 MYA - Quarternary

- Rāma, the great administrator, peaceful and perfect man bordering on divinity - Modern Man 0.01 - 2.6 MYA - Quarternary

- Balarāma, the man with the plough 0.01 - 2.6 MYA - Quarternary

- Krishna, a loving man as an astute politician to establish righteousness and punish the wicked 0.01 - 2.6 MYA - Quarternary

- Kalki, the mystical man to appear

Table 1 Vedic Timeline and Corresponding Geological Timeline of Ten Incarnations Advani (1992), http://www.americanchronicle.com/articles/view/101713

\begin{tabular}{|c|c|c|c|c|}
\hline $\begin{array}{l}\text { Sl. } \\
\text { No. }\end{array}$ & $\begin{array}{l}\text { Name of the } \\
\text { Incarnation }\end{array}$ & $\begin{array}{c}\text { Vedic } \\
\text { Timeline }\end{array}$ & $\begin{array}{l}\text { Geological } \\
\text { Timeline }\end{array}$ & Evolution \\
\hline 1 & $\begin{array}{c}\text { Matsya (Fish) } \\
\text { Aquatic Organism }\end{array}$ & $\begin{array}{c}\text { Beginning of Vaivasvata } \\
\text { Manvantara }\end{array}$ & $\begin{array}{l}\text { PreCambrian - Silurian- } \\
500 \text { - } 550 \text { MYA }\end{array}$ & $\begin{array}{l}\text { First developed life of biological } \\
\text { evolution in Geological Time } \\
\text { Scale is 'fish'. }\end{array}$ \\
\hline 2 & $\begin{array}{c}\text { Kurma (Tortoise) } \\
\text { Amphibion/Reptile }\end{array}$ & $\begin{array}{c}\text { Vaivasvata Manvantara } 2^{\text {nd }} \\
\text { Tretayuga }\end{array}$ & $\begin{array}{c}\text { Devonian/ } \\
\text { Mississippian } \\
358.9 \text { - 419.2 MYA }\end{array}$ & $\begin{array}{l}\text { In Geology, first reptiles come as } \\
\text { second important evolution }\end{array}$ \\
\hline 3 & $\begin{array}{c}\text { Varāha (Boar) Land } \\
\text { Animal } \\
\text { A vertebrate }\end{array}$ & $\begin{array}{c}\text { Vaivasvata Manvantara } \\
3^{\text {rd }} \text { Tretayuga }\end{array}$ & $\begin{array}{c}\text { Triassic } \\
200-250 \text { MYA }\end{array}$ & $\begin{array}{l}\text { Evolution of amphibian to the } \\
\text { land animal. }\end{array}$ \\
\hline
\end{tabular}


Stars In the Origin and Evolution of Species

\begin{tabular}{|c|c|c|c|c|}
\hline 4 & $\begin{array}{c}\text { Narasimha } \\
\text { (Half Man and Half Lion) }\end{array}$ & $\begin{array}{l}\text { Vaivasvata Manvantara } \\
\text { 7th Tretayuga }\end{array}$ & $\begin{array}{l}\text { Cretacious } \\
66-56 \text { MYA }\end{array}$ & $\begin{array}{l}\text { In Geology, no such evidences are } \\
\text { mentioned. It may have been } \\
\text { related with Ape Man. }\end{array}$ \\
\hline 6 & $\begin{array}{c}\text { Parasurāma } \\
\text { (Tall Man with Axe) }\end{array}$ & $\begin{array}{c}\text { Vaivasvata Manvantara } \\
\text { 19th Tretayuga }\end{array}$ & $\begin{array}{c}\text { Quarternary } \\
0.01-2.6 \text { MYA }\end{array}$ & $\begin{array}{l}\text { It has similarities with the first } \\
\text { modern man originated in the } \\
\text { Iron Age }\end{array}$ \\
\hline 7 & $\begin{array}{c}\text { Rāma } \\
\text { Perfect Human }\end{array}$ & $\begin{array}{c}\text { Vaivasvata Manvantara } \\
\text { 24th Tretayuga }\end{array}$ & $\begin{array}{l}\text { Quarternary } \\
0.01 \text { - 2.6 MYA }\end{array}$ & $\begin{array}{l}\text { Modern man with } \\
\text { administrative and rulership } \\
\text { abilities with all righteousness. }\end{array}$ \\
\hline 8 & $\begin{array}{c}\text { Balarāma } \\
\text { With Plough }\end{array}$ & $\begin{array}{c}\text { Vaivasvata Manvantara } \\
28^{\text {th }} \text { Tretayuga }\end{array}$ & $\begin{array}{l}\text { Quarternary } \\
0.01-2.6 \text { MYA }\end{array}$ & $\begin{array}{l}\text { Beginning of agriculture and } \\
\text { human civilisation and growth } \\
\text { of economy with all } \\
\text { righteousness }\end{array}$ \\
\hline 9 & $\begin{array}{c}\text { Lord Krishna } \\
\text { (Embodiment of Divivnity) }\end{array}$ & $\begin{array}{c}\text { Vaivasvata Manvantara } \\
28^{\text {th }} \text { Dwaparayuga }\end{array}$ & $\begin{array}{c}\text { Quarternary } \\
0.01-2.6 \text { MYA }\end{array}$ & $\begin{array}{l}\text { Domestication of animals and } \\
\text { development of economy with } \\
\text { a distinct mark of } \\
\text { advancement in civilisation } \\
\text { and upliftment of society }\end{array}$ \\
\hline 10 & $\begin{array}{c}\text { Kalki } \\
\text { (Yet to arrive) }\end{array}$ & $\begin{array}{c}\text { Vaivasvata Manvantara } \\
\text { End of } 28^{\text {th }} \text { Kaliyuga }\end{array}$ & $\begin{array}{c}\text { Quarternary } \\
\text { 0.00 MYA }\end{array}$ & $\begin{array}{l}\text { Wickedness, foul play and } \\
\text { immoral character and chaos } \\
\text { predominates and reaches } \\
\text { pinnacle in all walks of life. }\end{array}$ \\
\hline
\end{tabular}

\section{TOTAL NUMBER OF SPECIES: HINDUISM AND SCIENCE}

Vishnu Purana (between 100 BCE \& 100 CE) is one of the 18 major Purana texts of Hinduism in which it is mentioned the number of Species on earth to be around 84 Lakh or 8.4 million (Table 2) Life Forms on Earth in Science.

\begin{tabular}{|cc|}
\hline Table 2 Classification of Species in Hinduism \\
\hline Category & \# Of Species \\
\hline Water Born & 900,000 \\
\hline Immovables [Trees, plants] & $2,000,000$ \\
\hline Microbes, Insects, reptiles & $1,100,000$ \\
\hline Birds & $1,000,000$ \\
\hline Animals [Four Legged] & $3,000,000$ \\
\hline Humans & 400,000 \\
\hline Total & $\mathbf{8 . 4}$ million \\
\hline
\end{tabular}

The same number and classification can also found in many other texts like Karma Vipaka and Padma Purana as well. Recent researchers have found that there are around 8.7 million Species, but with around 15\% variation Positive or negative. Scientists also affirm that new species come to existence and go extinct all the time. Scientists Classify Life forms as follows (Table 3) Life Forms on Earth in Science. 
Table 3 Classification of Species in Science

\begin{tabular}{|c|c|}
\hline Category & \# Of Species \\
\hline Animals & 7.77 million \\
\hline Fungi & 0.61 million \\
\hline Plants & 0.30 million \\
\hline Protozoa & 0.04 million \\
\hline Chromists & 0.03 million \\
\hline Total & $\mathbf{8 . 7 5}$ million \\
\hline
\end{tabular}

Though, there is not much difference in the total number of Species mentioned in the scriptures (8.4 million) and the recent Scientific research (8.7 million), the classification of species in both are very much different and difficult to compare the numbers in each classification.

Vedic Science is holistic science. The Vedas mention there are 8.4 million species of life and the soul is continuously passing through the different species according to its destiny accrued due to its actions and reactions to objective environment of forces, under divine supervision. The Bhagavad Gita in Chapter 2, Verse 22 says that just as one gives up an old shirt to put on a new one, the soul gives up an old body to acquire a new kind of a body The Bhagavad Gita. Thus, there are 8.4 million (84 lakh) types of bodies, out of which the soul assumes a body at the time of death and birth as human being is considered unique and divine with opportunities to evolve spiritually to attain liberation from death-birth cycle through transcendental consciousness by raising the fundamental frequency of 7.83 $\mathrm{Hz}$ (Schumann Resonance) in him to the level of infinity in tune with $\mathrm{E}=\mathrm{mc} 2$.

\section{CAMBRIAN EXPLOSION}

Geological time scale indicates that Cambrian explosion occurred around 540 million years ago. Around 540 million years ago, during the 20 -million-year period of Cambrian explosion, presently existing phyla of different classes of animals as vertebrates, arachnids and molluscs of animal kingdom appeared suddenly and further they arrived not in sequence from simple to more complex forms, but appeared almost simultaneously. Cambrian explosion was rapid in geological terms, was triggered by many factors. The basic problem is that 'Natural Selection' is a slow accumulation of changes, whereas a new phylum as seen in Cambrian explosion appeared suddenly. According to 'Natural Selection' it should take longer than a new class, longer than a new order, longer than a new family, longer than a new genus, longer than emergence of a new species but the sudden occurrence of high-level complexity of organisms without precedents is perhaps implying unusual evolutionary mechanisms. Therefore, the mechanism of advanced panspermia alone could have been responsible for such developments. The Cambrian explosion as well as the origin and evolution of new species is evidenced by the circumstance that a close look at the Geological Time Scale reveals the role of climatic changes occurring due to synchronisation structure of massive planetary pair Jupiter- Saturn orbital resonance of 5:2 with simultaneous evolution of bio-sphere. Stars give out elements, at different phases of their life cycles running from a few millions of years to billions of years, constituting the inorganic chemistry available to us in the universe coupled 
with the special features of Cambrian Explosion is being observed as a plausible cause for the panspermia origin of different species with specific genetic sequences at different phases of Geological Time Scales.

Life on Earth may have been carried here in phases in streams of star dust propelled at very great velocities throughout planetary systems including on the mother earth for evolution due to Jupiter-Saturn orbital resonance causing climate changes at regular geologic periods providing diversification of species in contrast to Wesson's concept of continued arrival of living organisms to Earth. Once life began on earth, it could proliferate until it filled the planet. This is the correct of the matter is evidenced by a close look at the Geologic Time Scale (Figure 4).

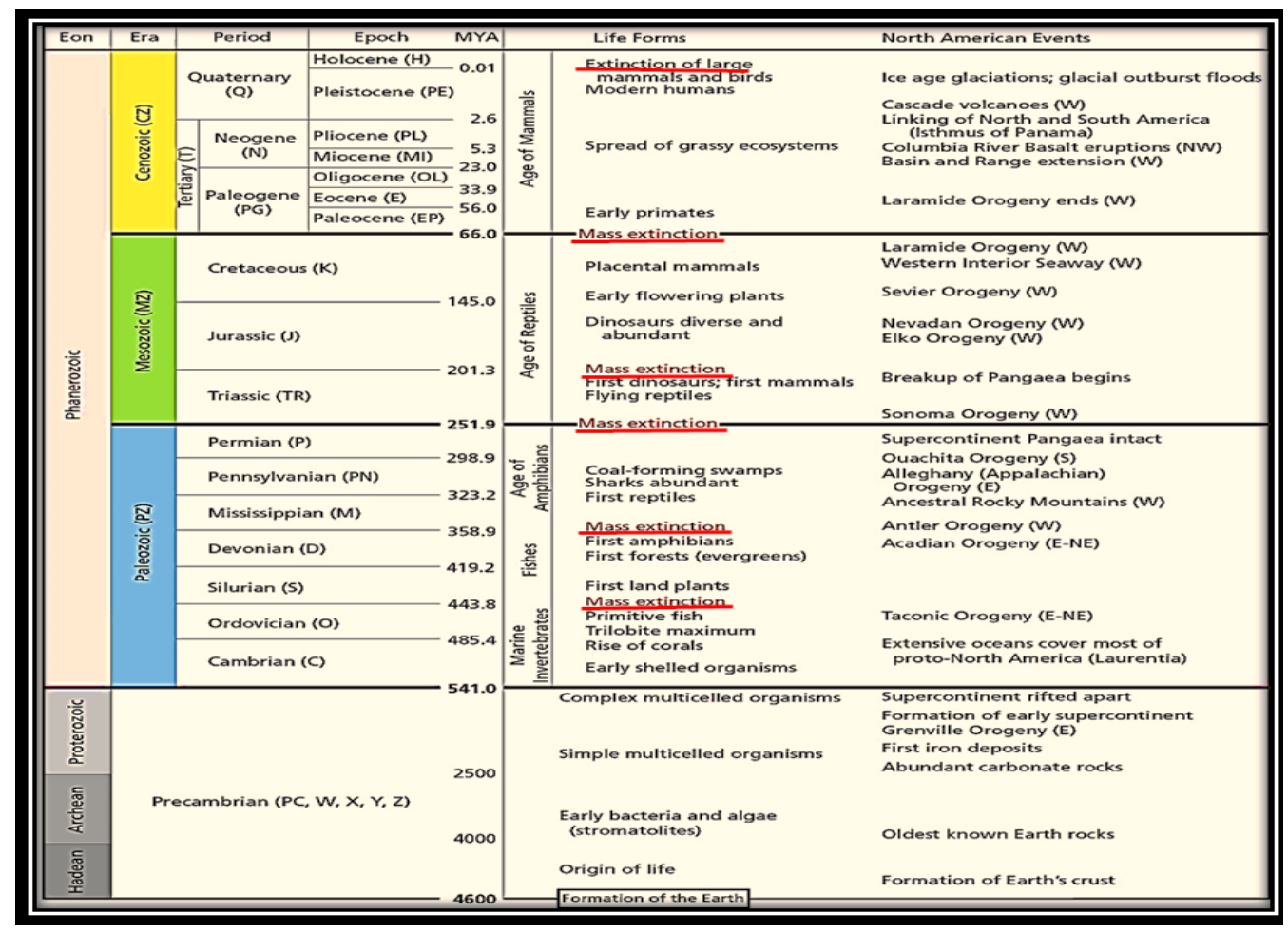

Figure 4 Geological Time Scale

Geologic Time Scale reveals, that the geological time 'Periods' are multiples of $\sim 20$ million years' periodicity, the 'Eras' are multiples of $\sim 60$ million years' periodicity and the 'Eons' are multiples of $\sim 600$ million years' periodicity. Even the 'Big Five Mass Extinctions' of species can also be observed to have occurred approximately at regular intervals of $\sim 60$ million years or multiples of 60 million years in Ordovician-Silurian extinction $\sim 444$ million years ago, Late Devonian extinction - 383-359 million years ago, Permian-Triassic extinction $\sim 252$ million years ago, Triassic-Jurassic extinction $\sim 201$ million years' ago. CretaceousPaleogene extinction - 66 million years ago, and Extinction today. There is other evidence for the coincidence, namely, K-T Boundary 65 million years ago, extinction of the dinosaurs and rise of small mammals) and the now well-established 26million-year periodicity (Galactic Tide-Holmes's cycle) with cometary impacts coinciding with mass extinction events (Clube et al., 1996) and evolution of all species (Napier et al., 2007). This affords a striking scientific phenomenon of a plausible explanation. 


\section{SCHUMANN'S RESONANCE}

German physicist Winfried Otto Schumann (1952) predicted 'Schumann Resonances' of a frequency of $7.83 \mathrm{~Hz}$. which are natural waves excited by lightning strikes in the cavity between the Earth's surface and the ionosphere and the resonant properties of this terrestrial cavity https://interestingengineering.com/what-is-the-schumann-resonance. All species on the earth resonate harmonically with the Schumann's Resonance in evolution except human beings whose brain wave is fundamental. Everything from our brain waves and biorhythms to our states of consciousness are directly correlated to the Earth's frequencies. Our entire biological system, the brain and the earth itself work on the same frequencies (Figure 5).

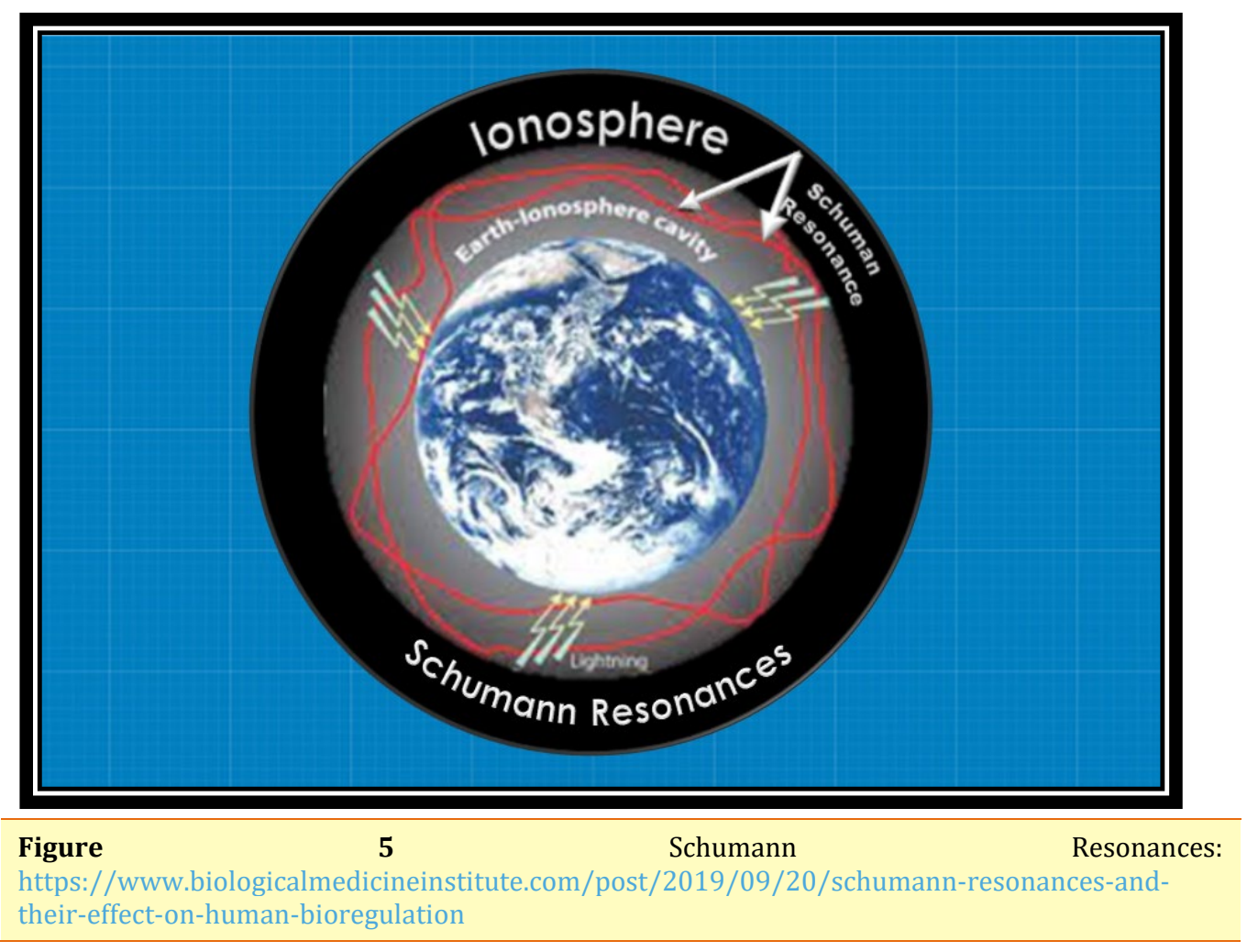

A $7.83 \mathrm{~Hz}$ frequency has apparently has matched that of the human brain's average alpha/theta brainwave frequency. Tuning into $7.83 \mathrm{~Hz}$, the planet's own magnetic frequency people experience benefits like enhanced learning/memory, body rejuvenation, balance, improved stress tolerance, anti-jetlag, anti-mind control, and grounding. It is the fundamental waveform from which other waveforms may-be generated. It is now an accepted fact in medicine that every single organ and organelle in the body is constantly vibrating. Tesla also spoke of this frequency, "Alpha waves in the human brain are between 6 and 8 hertz. The wave frequency of the human cavity resonates between 6 and 8 hertz. All biological systems operate in the same frequency range. The human brain's alpha waves function in this range and the electrical resonance of the earth is between 6 and 8 hertz. Thus, our entire biological system - the brain and the earth itself - work on the same frequencies. If we can control that resonate system electronically, we can 
directly control the entire mental system of humankind". C Price (2016), J Jackson (1998):

Human beings appeared on earth only 2 million years ago whose average alpha/theta brainwave frequency matching with Schumann's Resonance of $7.83 \mathrm{~Hz}$. Such of those species which appeared on earth a little prior to Humans like several hominid groups during the last few million years exhibiting no link to Homo sapiens and the genetic make-up of Neanderthals, closest to humans in their brain's frequency are neither ancestors of humans nor match with humans of immense intellectual capacities and capabilities. This is mainly due to the stars giving out elements, at different phases of their life cycles running from a few millions of years to billions of years in supporting evolution of species as delineated in the Geological Time Scale.

\section{COMPLEXITY OF HUMAN BRAIN}

Human beings are unique in evolution. While the basic genetic makeup of the human brain has not changed for the last several thousands of years, but we observe significant development of human thinking and consciousness, the intelligence varying from 'less intelligent to intelligence square'. This variation in intelligence is, plausibly, due to utilisation of the so called 'junk DNA' which is no longer considered 'junk' as recent researches hint. Evolution in human beings consists of 'Physical Evolution' and evolution of development of thinking and consciousness. Physical evolution may be probably due to functional DNA (15\%), comprising of survival, sex and control, which is common to all species including humans, while development of thinking and consciousness is exclusively human, for example, concern about the environment, climate change and the Earth's future probably due to the use of "junk DNA' (non-functional DNA about 85\%).

Recent researches in this regard hint that heart sends more signals to the brain than the brain sends to the heart and seem to possess a greater effect on brain function is visible in the domain of consciousness and even influences memory power and problem solving. Large regions of the human genome, once thought to be useless junk, work to keep our thinking and consciousness, the intelligence alive. "The heart is really the source of emotional intelligence, transferring intelligence to emotions and strengthening our ability to manage them" Rollin McCraty (2003). "Technology isn't going to shift the problems we have in society and the planet-it's going to take a shift of consciousness for that to happen" https://goop.com.

\section{RESULTS AND DISCUSSION}

This study of 'Stars in the Origin and Evolution of Species' is based on the principle underlying the selective adaptation of celestial bodies of solar system for its studies in 'Jyotish' (Astrology), one of the six Vedāngas and ancillary of most ancient Vedas of Hinduism is that they are responsible for the sunlight on earth. Certain celestial bodies of solar system, namely, the Sun (A Star),), Mercury, Venus (Interior Planets), the Moon (Satellite of the Earth) together with its two Nodes (North and South Lunar Nodes), Mars, Jupiter and Saturn (Exterior Planets) are selectively adapted into Jyotish as means of its studies purely rests on the effects of electromagnetism in the form of sunlight (electromagnetic wave) to the Earth. Sunlight is essential for flora and fauna to flourish on earth. Earth receives sunlight from the solar system, directly from the sun, by reflection from the interior planets, by deflection and reflection from exterior planets and finally from the moon by reflection and modulated light due to waxing and waning (Figure 6). 


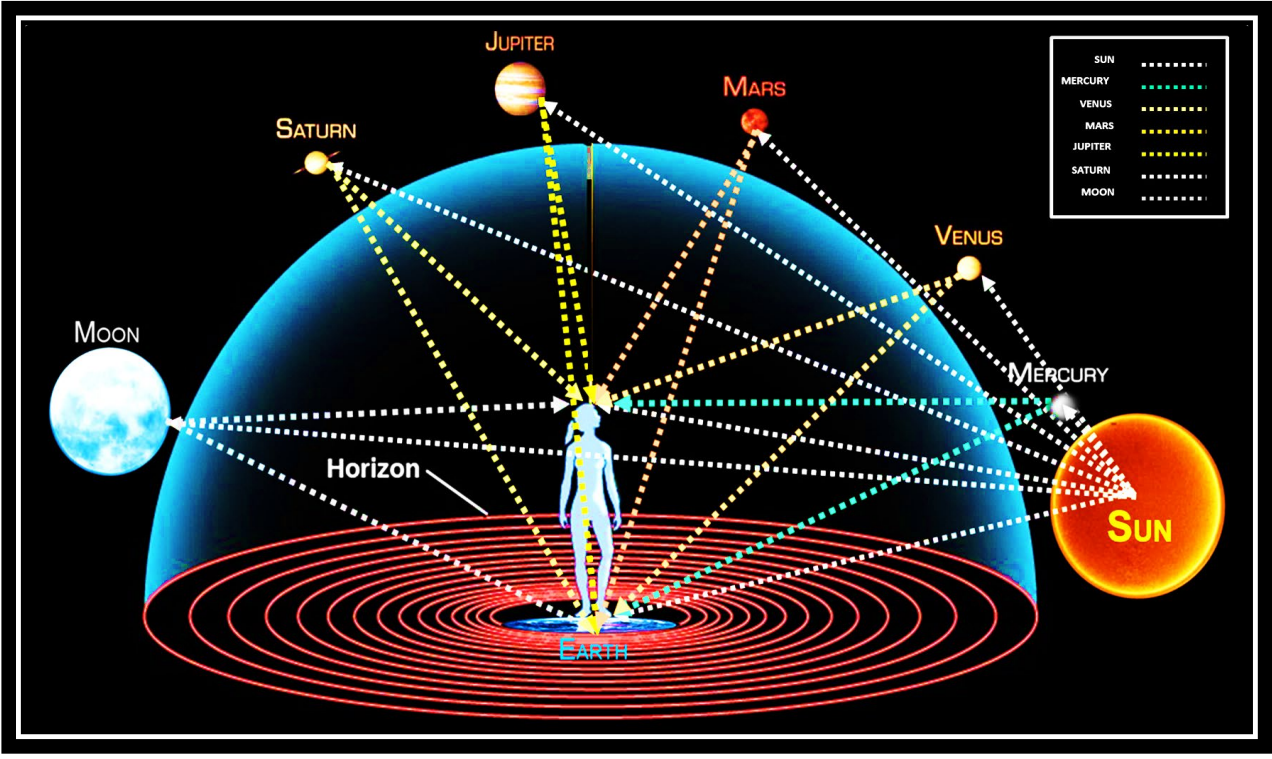

Figure 6 Sun Light incident on the planets and Moon being reflected on to the Earth and Life Living on it.

Sunlight is an electromagnetic wave of light with its natural frequencies/wavelengths and energies. One of the waves is an oscillating magnetic field; the other is an oscillating electric field with their wavelengths/frequencies and energy which interact with matter. Electromagnetic Force does a miracle in forming matter. "Magnetism is one of the fundamental properties of the Earth; it is native and fundamental to our planet's existence" (Figure 7).

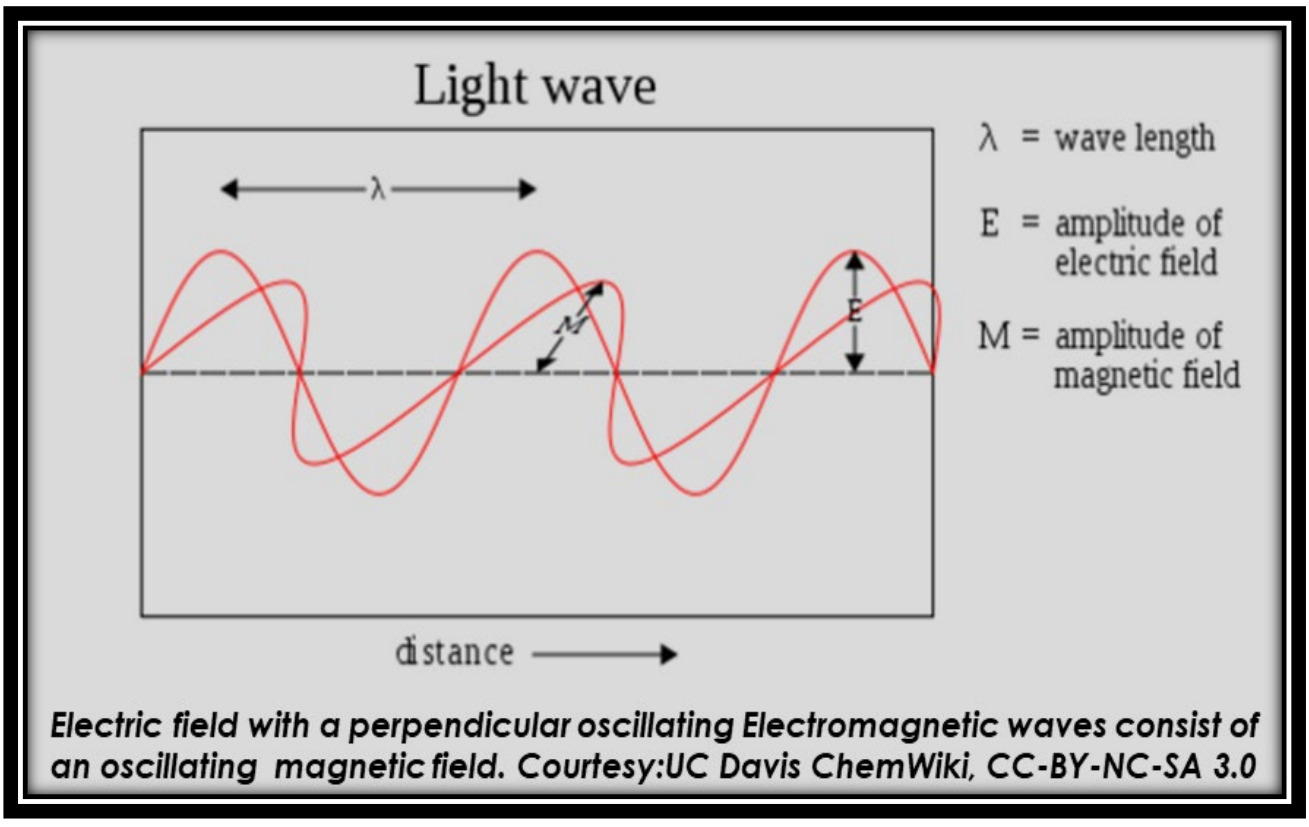

Figure 7 Sunlight is an Electromagnetic Wave of Light: Electromagnetic waves consist of an oscillating electric field with a perpendicular oscillating magnetic field. Credit: Image from UC Davis ChemWiki, CC-BY-NC-SA 3.0

Stars give out elements, constituting the inorganic chemistry available to us in the universe. It is through photosynthesis that light does its magical trick: the magic 
of transformation of matter -- carbon dioxide and water -- into life; the magic of transformation of light into living energy that transfers from plants to all animals. The miracle of sunlight transforms matter into life and life transforms into energy. Thus, life is an emergent property of matter (Figure 8: Sunlight Transforms Matter into Life and in turn Transforms into Energy) (A Vedānga).

The stars give out elements in phases of their life cycles ranging from a few million years to billions of years' result in the origin of variety of species as delineated in the Geological Time Scale. Geological Time Scale of Evolution of Species plausibly reflects Periodic Table of Elements. This hypothesis of evolution explains the critical milestones in the development of advanced life on Earth during the Cambrian explosion.

Planets raise tides in the gases of the Sun. It results in the creation of sunspots and their particle emissions i.e., Interplanetary Magnetic Field (IMF) which then travel across interplanetary space strikes the Earth's magnetosphere, ringing it like a bell. Earth's magnetosphere contains a wide range of frequencies which are then telegraphed to the species living on the earth via their neural network and the species which are on that specific frequency alone perceive and respond in evolution just as a radio in our homes. Thus, solar disturbances and their particle emissions are the most probable link between biological and extra-terrestrial events.

Human beings appeared on earth only 2 million years ago whose average with Schumann's Resonance of $7.83 \mathrm{~Hz}$. Such of those species which appeared on earth a little prior to Humans like several hominid groups during the last few million years exhibiting no link to Homo sapiens and the genetic make-up of Neanderthals, closest to humans perhaps in their brain's frequency are neither ancestors of humans nor match with humans of immense intellectual capacities and capabilities. This is mainly due to the stars giving out elements, at different phases of their life cycles running from a few millions of years to billions of years in supporting evolution of species as delineated in the Geological Time Scale. Evolution has come to a grinding halt with the appearance of humans. Though no change is perceivable in the genetic makeup of the human brain, "junk DNA' sends more signals to the brain than the brain sends to the heart and plausibly possess a greater effect on brain function visible in the domain of consciousness and even influences memory power and problem solving.

\section{CONCLUSION}

The stars give out elements in phases of their life cycles ranging from a few million years to billions of years' result in the origin of variety of species as delineated in the Geological Time Scale. Thus, Geological Time Scale of Evolution of Species plausibly reflects Periodic Table of Elements which fact explains the hypothesis of evolution of advanced life on Earth during the Cambrian explosion. All species harmonically respond to the earth's magnetosphere in resonance except humans who are fundamental as their alpha/theta brainwave frequency matching with the earth pulsating at $7.83 \mathrm{~Hz}$. British geneticist and evolutionary biologist, J B S Haldane, suggested that Dasāvatār (Ten incarnations) gave a "rough idea" of vertebrate evolution: a fish, a tortoise, a boar, a man-lion, a dwarf and then four men (Kalki is not yet born). He observed that the Dasāvatār (ten principal incarnations of Lord Vishnu) are a true sequential depiction of the great unfolding of evolution. These avatārs of Vishnu show an uncanny similarity to the biological theory of evolution of life on earth. The theory of evolution of man! Hinduism was the first to explain the 'Theory of Evolution of Life on Earth'. 


\section{CONFLICTS OF INTEREST}

The authors declare that they have no conflict of interest.

\section{ACKNOWLEDGEMENTS}

I would like to acknowledge my son, Prof. Y. V. Ramana Rao, M. Tech., Ph. D, Department of Electronics and Communication Engineering, College of Engineering, Anna University, Chennai for the careful proofreading of the manuscript and offer of many valuable suggestions.

\section{REFERENCES}

C Price (2016). ELF Electromagnetic Waves from Lightning doi: 10.3390/atmos 7090116

Heart Energy Field - 4 Ways The Heart \& Brain ... - Goop

J Jackson (1998). Classical Electrodynamics 3rd Edt. Wiley

Jennifer A. Johnson (Feb 2019), Populating the periodic table: Nucleosynthesis of the elements, Science 01, Vol. 363, Issue 6426, pp. 474-478 DOI: 10.1126/science. aau 9540

Life Cycles of Stars Retrieved from http://imagine.gsfc.nasa.gov/educators/lifecycles/stars.html

Life Forms on Earth in Science: AumAmen Retrieved from http://aumamen.com > Hinduism > Topics)

Life Forms on Earth in Science: AumAmen Retrieved from http://aumamen.com > Hinduism > Topics)

McCraty(2003).The_Energetic_Heart_Bioelectromagnetic_Interactions_Within_and _Between_People Rollin Retrieved from https://www.academia.edu/7289819/

Populating the periodic table Retrieved from https://blog.sdss.org/author/jajohnson51/

Sunlight in the genesis of principles of Jyotish (A Vedānga) Retrieved from https://www.jyotishajournal.com/pdf/2019/vol4issue2/PartA/4-2-8229.pdf

The Bhagavad Gita in Chapter 2, Verse 22

The India magazine of her people and culture, Volume 13, A. H. Advani,1992, p. 92

Twinkle, Twinkle, (1947). Little Star by Jane Taylor Source: The Golden Book of Poetry. Retrieved from https://www.poetryfoundation.org/poems/43200/twinkle-twinkle-littlestar

Vedic Thought and Modern Genetics on Consanguinity BioMed Research Journal BMRJ, 5(2): 408-412 www.scitcentral.com

What is the Schumann Resonance? Retrieved from https://interestingengineering.com/what-is-the-schumann-resonance

http://www.americanchronicle.com/articles/view/101713

https://biologos.org/common-questions/does-the-cambrian-explosion-pose-achallenge-to-evolution/

https://goop.com > wellness > spirituality > could-the-en... 


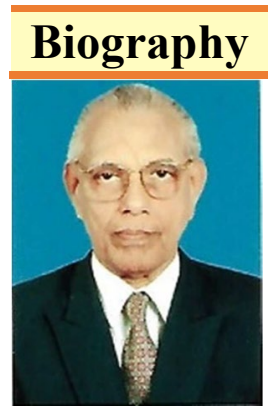

Y.V.S.Rao, , Ph.D., FIE., C. Eng. (I), an octogenarian, was born in 1938. He is a Chartered Mining Engineer, Govt. of India Certified Mines Manager, Certified Mines Surveyor, Astronomer, Author and Astrologer. He was a faculty member of Mining Engineering Department of Osmania University, Hyderabad and later in Geology Department of S. V. University, Tirupati, India. Visited Leitz Electron Microscopy Application Lab, West Germany for 4-weeks on deputation. After retirement, as Executive Engineer, University Science and Instrumentation Department, he served as Visiting Professor of Jyotish (Astronomy and Astrology), Central Sanskrit University, Tirupati. He is the author of several books on VedaSciences published by LAP Academic Publications, West Germany and by Sri Venkateswara Vedic University, Tirupati. and has several research papers to his credit published in International Journals of UK and USA (ORCID Number: 00000003-2536-2027). He is a member of several professional bodies besides being a Member, National Manuscripts Mission ('namami'), Ministry of Culture, Government of Inia and a Fellow of Institution of Engineers (India), Mining and Metallurgy Division and Member of Electron Microscopy Society of India 